\section{Double-balloon enteroscopy-ERCP rendezvous technique}

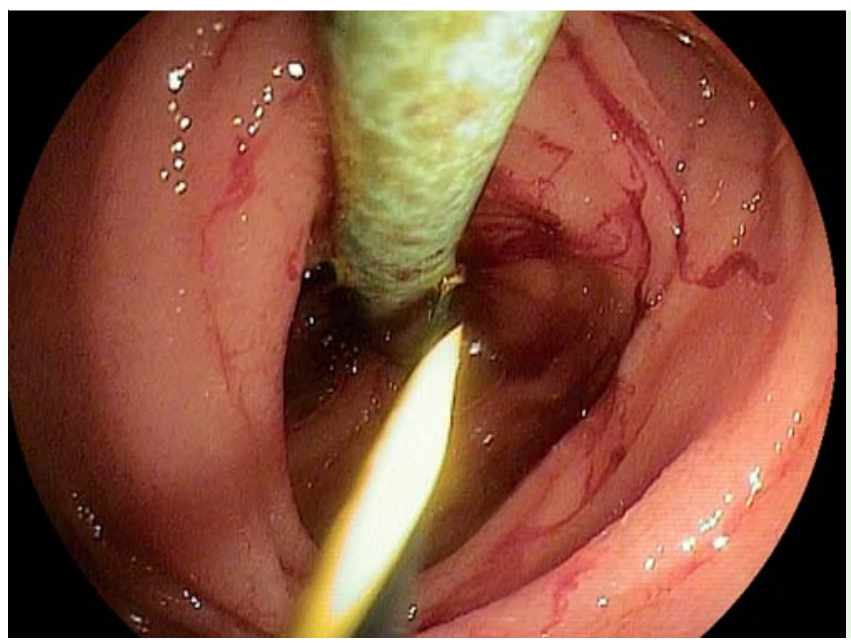

Fig. 1 A 0.035-inch guide wire with tungsten-coated end being advanced percutaneously into the jejunum across a hepaticojejunostomy stricture in a 22-year-old woman with autoimmune hepatitis and history of two liver transplantations with Roux-en-Y hepaticojejunostomy.
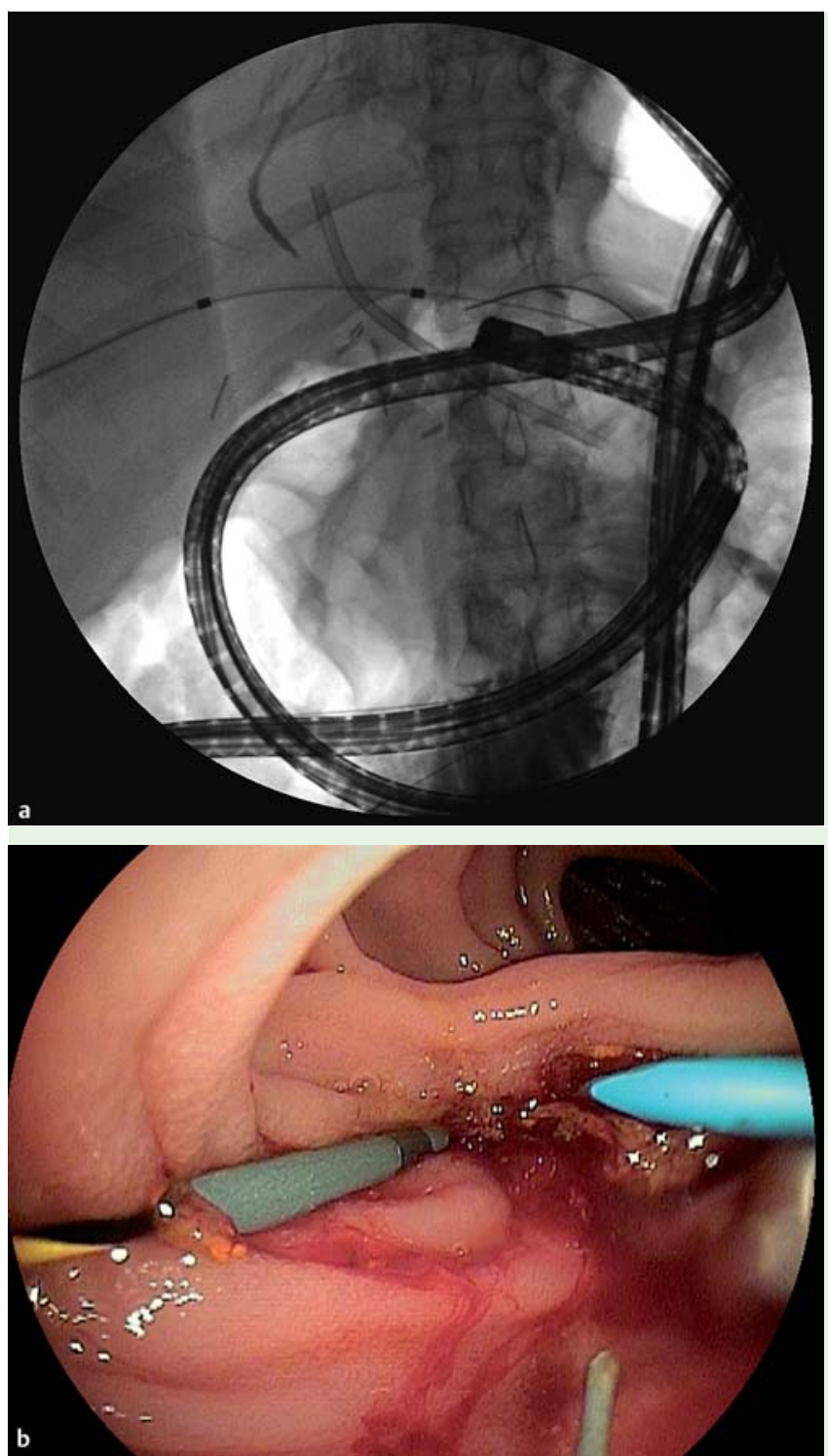

Endoscopic retrograde cholangiopancreatography (ERCP) in patients with surgically altered upper gastrointestinal anatomy such as Roux-en-Y anastomosis is challenging [1]. The use of double-balloon endoscopy (DBE) for ERCP in patients with surgically altered anatomy has been shown to be safe and feasible [2-4]. Here we present the concept of DBE-ERCP rendezvous technique with combined endoscopic-percutaneous placement of biliary stents in two patients.

A 22-year-old woman with autoimmune hepatitis, who had undergone two previous liver transplantations with Rouxen-Y hepaticojejunostomy, presented with bile duct strictures. A percutaneous transhepatic drain (PCTD) had been placed to relieve the bile duct strictures but she had persistent, severe abdominal pain at the site of the PCTD. Thus, she was referred to us for DBE-assisted ERCP to attempt internalization of the biliary drainage. The DBE was advanced to the afferent limb where two percutaneous transhepatic cholangiography stents were seen exiting the hepaticojejunostomy. Due to massive looping of the endoscope it was impossible to advance any stents through the scope. Thus it was decided to place the endoscopic stents from outside, i.e., through the skin. Two wires with floppy ends were advanced percutaneously into the jejunum across the hepaticojejunostomy ( $\bullet$ Fig. 1 ). The external/internal stents were then removed over the wires and two 10-Fr, 7-cm long plastic stents (Cook, Winston-Salem, North Carolina, USA) were inserted over the wire ( Fig. 2). The patient had an uneventful recovery.

A 75-year-old man with a history of pancreatic cancer who had undergone a Whipple procedure 5 years previously was admitted because of jaundice and a recurrent pancreatic cancer at the hepaticojejunostomy. A PCTD had been placed to relieve the obstruction. He was referred for DBE-ERCP to attempt internalization of the biliary drainage. Due to the presence of many adhesions and the looped scope position it was not possible to place internal stents. The wire was kept tight inside the jejunum with biopsy forceps ( Fig.3), while an endoscopic 8-mm diameter, 60-mm long, self-expanding metal stent (Boston Scientific, Natick, Massachusetts, USA) was placed percutaneously under endoscopic and radiologic control ( $\bullet$ Fig.4).

Balloon-assisted enteroscopy-ERCP is now an accepted interventional modality in patients with complex postsurgical 


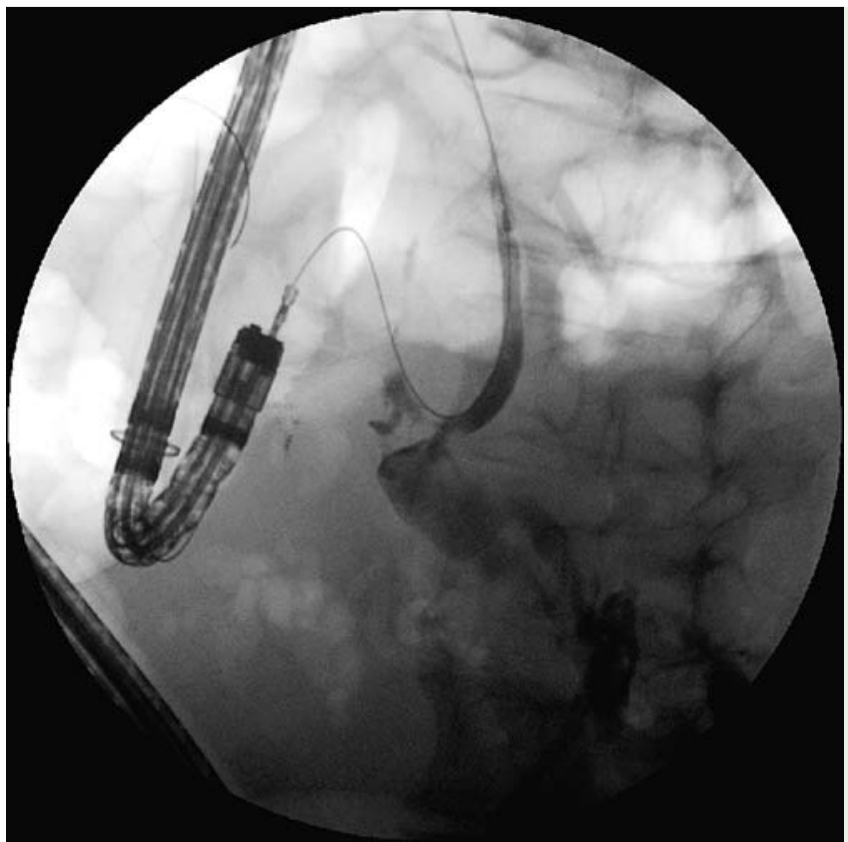

Fig. 3 Wire held in place with a biopsy forceps and advanced through the enteroscope in a 75-year-old man with history of pancreatic cancer, Whipple procedure, jaundice and a recurrent pancreatic cancer at the hepaticojejunostomy.

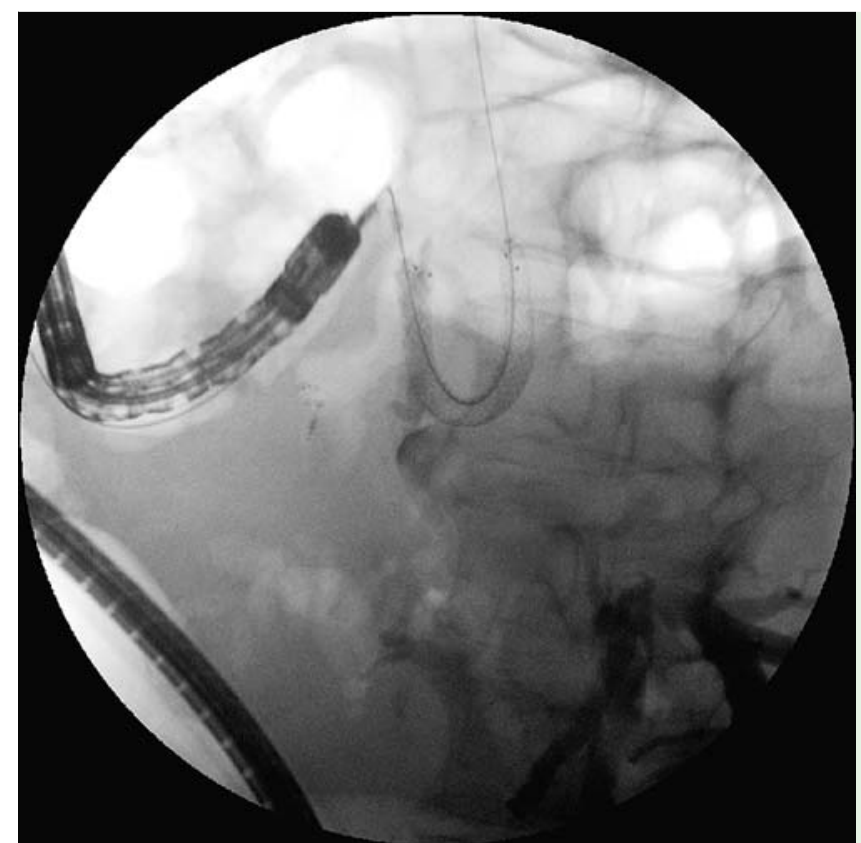

Fig. 4 A self-expandable metal stent advanced from the skin and placed under endoscopic and fluoroscopic control.

anatomy [2-4]. However, the passage of dilating balloons, and larger-diameter plastic and metal stents, is limited by the size of the working channel of the enteroscope. In addition, when the scope is torqued and looped, even the passage of smaller-caliber accessories may be impos-
Endoscopy_UCTN_Code_TTT_1AR_2AB

\section{Competing interests: None}

\section{K. Mönkemüller, D. Popa, B. McGuire, J. Ramesh, C. M. Wilcox}

Division of Gastroenterology and Hepatology, Basil Hirschowitz Endoscopic Center of Excellence, University of Alabama, Birmingham, Alabama, United States of America

\section{References}

1 Saleem A, Baron TH, Gostout CJ et al. Endoscopic retrograde cholangiopancreatography using a single-balloon enteroscope in patients with altered Roux-en-Y anatomy. Endoscopy 2010; 42: 656-660

2 Mönkemüller K, Fry LC, Bellutti M et al. ERCP with the double balloon enteroscope in patients with Roux-en-Y anastomosis. Surg Endosc 2009; 23: 1961 - 1967

3 Koornstra JJ, Fry L, Mönkemüller K. ERCP with the balloon-assisted enteroscopy technique: a systematic review. Dig Dis 2008; 26: $324-329$

4 Dellon ES, Kohn GP, Morgan DR et al. Endoscopic retrograde cholangiopancreatography with single-balloon enteroscopy is feasible in patients with a prior Roux-en-Y anastomosis. Dig Dis Sci 2009; 4: $1798-$ 1803

\section{Bibliography}

Dol http://dx.doi.org/

10.1055/s-0033-1344329

Endoscopy 2013; 45: E333-E334

(c) Georg Thieme Verlag KG

Stuttgart · New York

ISSN 0013-726X

\section{Corresponding author \\ K. Mönkemüller}

Division of Gastroenterology and Hepatology Basil Hirschowitz Endoscopic Center of Excellence Endoscopy Unit, JT 664 619 19th Street S

Birmingham

AL 35249

USA

klaus1@uab.edu 